\title{
Uso de plantas medicinais na região de Alto Paraíso de Goiás, GO, Brasil
}

\author{
Cynthia Domingues de Souza ${ }^{1,3}$ e Jeanine Maria Felfili ${ }^{2}$
}

Recebido em 10/11/2003. Aceito em 22/07/2005.

\begin{abstract}
RESUMO - (Uso de plantas medicinais na região de Alto Paraíso de Goiás, GO, Brasil). Os conhecimentos tradicionais dos usos mais comuns dados aos vegetais podem ser resgatados pela etnobotânica e utilizados para a valorização das plantas do Cerrado no processo de desenvolvimento econômico. Este estudo foi conduzido no município de Alto Paraíso de Goiás, localizado na microrregião denominada Chapada dos Veadeiros, a uma distância de $230 \mathrm{~km}$ de Brasília. O levantamento etnobotânico teve como alvo comunidades do entorno do Parque Nacional da Chapada dos Veadeiros e da cidade de Alto Paraíso. Foram realizadas entrevistas em aberto com os moradores locais, tentando buscar informações em níveis sócio-culturais distintos, enfocando quais plantas são mais utilizadas e suas indicações no combate a enfermidades. Observou-se que as espécies vegetais do cerrado têm uma gama considerável de utilização humana para quase todos os estratos, ervas, arbustos e árvores. Quanto às espécies arbóreas, predomina a utilização da entrecasca e sementes. A comunidade utiliza a biodiversidade nativa uma vez que $69 \%$ das 103 espécies citadas pelos entrevistados como úteis pertenceram à flora nativa. No elenco das dez espécies medicinais mais utilizadas, foram coincidentes na indicação de todos os entrevistados: chapéu de couro (Echinodorus macrophyllus (Kunth) Micheli), arnica (Lychnophora ericoides Mart.), plantas nativas de porte herbáceo/arbustivo; as arbóreas nativas, jatobá (Hymenaea stigonocarpa Mart. ex Hayne), tingui (Magonia pubescens A. St.-Hil.) e o barbatimão (Stryphnodendron adstringens (Mart.) Coville) e duas ruderais, carrapicho (Acanthospermum australe (Loefl.) Kuntze) e mastruz (Chenopodium ambrosioides L.), de porte herbáceo/arbustivo. Outro ponto importante evidenciado foi que, apesar do grande potencial de exploração extrativista vegetal, estes recursos estão sendo utilizados de forma indiscriminada, sem um programa eficiente de manejo sustentado.
\end{abstract}

Palavras-chave : etnobotânica, plantas medicinais, Alto Paraíso de Goiás, Brasil

\begin{abstract}
The utilization of medicinal plants in the region of Alto Paraíso of Goiás, GO, Brazil). Ethnobotany allows rescuing traditional knowledge of the most common uses given to the plants. It therefore, adds an extra-value to the cerrado species in the context of the economic development. This study was conducted in Alto Paraiso de Goiás town, located in the Plateaux named Veadeiros, distant of $230 \mathrm{~km}$ from Brasília. An ethnobotanical survey was conducted around the National Park of "Chapada dos Veadeiros", in Alto Paraíso municipality and in the town itself. Open-ended interviews were carried out with several people, trying to cover the variety of sociocultural segments of the local society. Humans use a wide range of cerrado plant species from almost all the strata, herbs, shrubs and trees. The native biodiversity is used by the local people, with $69 \%$ of the 103 species quoted by them as useful plants, being native species. Amongst the top ten medicinal species ranked by the interviewed people, the following ones were quoted by everyone: chapéu de couro (Echinodorus macrophyllus (Kunth) Micheli), arnica (Lychnophora ericoides Mart.), native shrubs; jatobá (Hymenaea stigonocarpa Mart. ex Hayne), tingui (Magonia pubescens A. St.-Hil.) and barbatimão (Stryphnodendron adstringens (Mart.) Coville), native tree species and, two ruderal shrubs, carrapicho (Acanthospermum australe (Loefl.) Kuntze) and mastruz (Chenopodium ambrosioides L.). Besides the large potential for extrativism of plants, these resources are been depled without any plan for sustainable mangement.
\end{abstract}

Key words: ethnobotany, medicinal plants, Alto Paraiso de Goiás, Brazil

\section{Introdução}

O Brasil detém a maior diversidade biológica do mundo, contando com uma rica flora, despertando interesses de comunidades científicas internacionais para o estudo, conservação e utilização racional destes recursos. O bioma cerrado contém mais de 6.000 plantas vasculares (Mendonça et al. 1998), muitas delas com valor alimentício e medicinal (Almeida et al. 1998). No setor da medicina, as plantas tropicais fornecem material para a produção de analgésicos, tranqüili- zantes, diuréticos, laxativos e antibióticos entre outros. A comercialização mundial dos produtos secundários soma, em média, 200 milhões de dólares por ano (Meyers 1983; Principe 1985).

No Brasil, para a produção extrativa, através de dados oficiais levantados (IBGE) o valor da produção, em 1980 era de U\$ 290 mil, atingiu U\$ 940 mil em 1989 (IBGE 1984; 1985; 1987; 1992).

O estudo etnobotânico consiste na avaliação da interação humana com todos os aspectos do meio ambiente (Martin 1995), através de levantamentos nas

\footnotetext{
${ }^{1}$ Gerência Regional, Instituto Brasileiro do Meio Ambiente e dos Recursos Naturais Renováveis, IBAMA, Rua 229, 95, CEP 74605-090, Goiânia, GO, Brasil

2 Universidade de Brasília, Faculdade de Tecnologia, Departamento de Engenharia Florestal, CEP 70919-970, Brasília, DF, Brasil

3 Autor para correspondência: cynthiadomingues@pop.com.br
} 
comunidades tradicionais sobre a utilização das plantas na farmacopéia caseira e na economia doméstica. Também permitem inferir sobre eficácia dos produtos que atingem o mercado de produção de chás, xaropes, cremes e outros (Alexiades \& Sheldon 1996).

O estudo dos usos das plantas medicinais deve levar em consideração o contexto social e cultural no qual estes usos são encaixados (Herrick 1983; Elisabetsky 1986; Etkin 1988; 1990). Há uma carência muito grande de levantamentos etnobotânicos e de potencial extrativista no cerrado (Felfili et al. 1998), mas, grande parte da flora do cerrado tem sido amplamente explorado pelo conhecimento popular e, nos últimos anos, vem crescendo o aproveitamento de forma sistematizada através de associações comunitárias, produzindo medicamentos tais como: pomadas, xaropes, soluções tópicas cicatrizantes e fungicidas, soluções e comprimidos para tratamento de vermes, entre outros.

Alto Paraíso de Goiás, no nordeste do Estado, ainda é um município cuja economia é baseada na atividade rural nos moldes tradicionais da agricultura e pecuária de pesquena escala. Grande parte de sua população consiste de famílias que lá se estabeleceram há séculos, muitos deles ainda no ciclo da mineração do ouro e que lá tem vivido sem muito acesso a facilidades tecnológicas. Pressupõe-se que o conhecimento e o uso de plantas medicinais sejam amplos na comunidade.

O principal objetivo deste trabalho foi investigar quais plantas são utilizadas pelas populações urbanas e rurais do município de Alto Paraíso de Goiás para o tratamento das enfermidades com fitoterapia. Foi investigada também, a finalidade para as quais as plantas são utilizadas e a origem e hábito da flora medicinal.

\section{Material e métodos}

O município de Alto Paraíso de Goiás, GO situa-se no nordeste goiano, entre as coordenadas $14^{\circ}$ a $14^{\circ} 10^{\prime} \mathrm{S}$

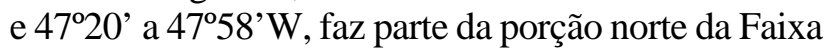
de Dobramentos e Cavalgamentos Brasília, na Província Estrutural do Tocantins (Dardenne \& Faria 1985). A região da Chapada dos Veadeiros está sob o domínio do Clima Tropical, sub-úmido (AW), segundo Köppen, com duas estações bem definidas: verão chuvoso entre os meses de outubro a abril e um inverno seco entre os meses de maio até meados de setembro. Esta região apresenta variações com o Clima Tropical de Altitude (CWa). As temperaturas médias anuais em
Alto Paraíso são estimadas em torno de 24 a $26^{\circ} \mathrm{C}$. Durante o inverno verificam-se temperaturas baixas, com a mínima absoluta entre 4 a $8^{\circ} \mathrm{C}$, em áreas situadas acima de 1.000 metros de altitude (Prefeitura de Alto Paraíso 1999). A região do estudo tem a predominância de Latossolo Vermelho-Amarelo, álico, (saturação de alumínio maior ou igual a 50\%) texturas argilosas e médias, ocorrendo sobre relevo plano e ondulado suave. Também ocupam grandes extensões os solos Litólicos álicos e distróficos, cascalhentos, textura arenosa e arenosa média, em relevo que varia de plano e suave ondulado a montanhoso e escarpado.

Os dados etnobotânicos foram registrados em comunidades do entorno do Parque Nacional da Chapada dos Veadeiros na cidade de Alto Paraíso, englobando a do Moinho. O alvo do estudo foram os moradores dos núcleos urbanos e rurais ressaltandose que em Alto Paraíso, assim como na comunidade do Moinho, muitos moradores são de origem e continuam trabalhando em atividades rurais, mas possuem residências no núcleo urbano por motivo de escolarização dos filhos. Procurou-se selecionar para as entrevistas, pessoas de níveis sócio-culturais e atividades ocupacionais distintas. Dentre as técnicas utilizadas para levantamentos etnobotânicos aplicáveis às plantas medicinais, destaca-se a adotada neste trabalho, que consiste em entrevistas abertas, concomitantemente com o posicionamento ou hierarquização de determinadas escolhas (Martin 1995; Prance 1991). Realizam-se conversas informais com membros da comunidade, posteriormente, estas informações são categorizadas iniciando então o trabalho de hierarquização das preferências, ou seja, as espécies utilizadas pela comunidade serão posicionadas em uma escala de preferência, neste caso.

Foram realizadas entrevistas com os moradores locais, onde se coletaram dados como o nome do entrevistado, idade, profissão, sexo e os usos das plantas. Foram entrevistados dois médicos, um veterinário, um advogado, um agrônomo, um fitoterapeuta, dois raizeiros, uma parteira, um parteiro, um viveirista, sete donas-de-casa, dois pedreiros, um dirigente de associação de classe, totalizando 20 pessoas. O presidente da associação comunitária, respondeu às questões após consulta a sua diretoria e associados de modo a representar ao máximo os associados. Todos os entrevistadores eram moradores da região há mais de um ano e a maioria nativos do local. Parte dos entrevistados foram profissionais cujo trabalho tem relação com fitoterapia e a outra parte 
foram usuários, nativos da região. Por ser uma cidade pequena, Alto Paraíso conta com poucos profissionais como médicos, agrônomos, assim como parteiras e fitoterapeutas.

Foram realizadas entrevistas em aberto (Martin 1995; Marimon \& Felfili 2001) questionando quais as plantas usadas, seus usos, e quando mencionado o uso medicinal, foi perguntado para quais enfermidades estas foram usadas. Estas entrevistas foram realizadas durante várias ocasiões ao longo de 12 meses, quando a primeira autora residiu na região para realizar este estudo. Na primeira entrevista buscou-se apenas um contato, explicando o objetivo do trabalho, solicitando que o entrevistado se apresentasse e falasse sobre sua experiência com plantas medicinais. Foi então, agendada uma série de entrevistas que variou conforme o entrevistado. Para os usuários, foram feitas mais duas entrevistas onde estes elencaram as plantas que usavam e descreveram seu uso. Foram feitas duas visitas aos locais de trabalho dos profissionais entrevistados onde seus trabalhos foram observados e efetuadas perguntas sobre sua experiência com plantas medicinais, participando, algumas vezes, pessoalmente dos tratamentos fitoterápicos oferecidos por um dos médicos entrevistados. A Associação Comunitária foi abordada por meio do seu presidente, que, na primeira visita quando da apresentação da primeira autora, a segunda quando esta repassou ao mesmo perguntas sobre a experiência da comunidade com plantas medicinais e este se prontificou a consultar a diretoria e demais moradores para então responder às questões. $\mathrm{Na}$ terceira visita, foram recolhidas as respostas.

Em seguida, foi elaborada uma listagem de todas as espécies citadas como medicinas. As espécies foram tratadas por seus nomes populares, com observação "in loco" pelos entrevistados para identificação dos exemplares de campo, quando nativas ou invasores de ambientes naturais ou alternativamente, nos canteiros, potes e jardins quando plantadas. Foi utilizada como base para a entrevista a listagem de plantas da Chapada dos Veadeiros, produzida pelo Projeto Biogeografia do Bioma Cerrado (Felfili et al. 1997) e a listagem das plantas de Alto Paraíso de Goiás (Munhoz \& Proença 1998). Foram então realizadas novas entrevistas onde cada entrevistado selecionou e hierarquizou as dez espécies mais importantes no seu uso cotidiano, conforme sugerido por Prance et al. (1987).

$\mathrm{Na}$ segunda etapa da pesquisa, direcionaram-se as entrevistas, uma por entrevistado, para que o entrevistado discorresse sobre as dez espécies medicinais mais utilizadas. Foi verificada a coincidência das espécies nomeadas pelos 20 entrevistados de modo a obter-se uma hierarquização da importância relativa atribuída às espécies (ver Marimon \& Felfili 2001) e, posteriormente, foi realizada pesquisa bibliográfica para aferição das informações e complementadas conforme Guarim-Neto et al. (2000) para espécies da família Sapindaceae em Mato Grosso.

Foi elaborada uma listagem dividida por espécies nativas do cerrado e exóticas, classificadas pelo hábito em herbáceas/arbustivas e arbóreas contendo todas as espécies mencionadas, nome científico, popular, usos.

\section{Resultados e discussão}

As espécies vegetais nativas utilizadas pela comunidade urbana/rural de Alto Paraíso pertencem a diferentes ambientes do bioma cerrado assim como algumas delas são exóticas ou pioneiras, colonizadoras de ambientes degradados, Tab 1. Das 103 espécies citadas no levantamento etnobotânico (Fig. 1), 31\% são exóticas, muito utilizadas, compondo garrafadas, chás, pomadas e banhos. Dentre estas, $8,7 \%$ são ruderais herbáceas/arbustivas e 14,5\% são espécies plantadas nas casas dos moradores. Algumas espécies utilizadas para a composição das garrafadas são adquiridas no comércio, 3,8\%. As nativas arbóreas somam 36\% das citações. O estudo etnobotânico evidenciou que a população da cidade e entorno de Alto Paraíso usa as plantas para fins fitoterápicos, seja para as enfermidades cotidianas, seja para trabalhos terapêuticos alternativos e por médicos naturalistas.

Apenas sete espécies foram citadas em comum por todos os entrevistados, representando $6,7 \%$ do total espécies mencionadas. São elas: carrapicho (Acanthospermum australe (Loefl.) Kuntze), mastruz (Chenopodium ambrosioides L.), sendo espécies denominadas exóticas ou ruderais, de porte herbáceo/ arbustivo; chapéu de couro (Echinodorus macrophyllus (Kunth) Micheli), arnica (Lychnophora ericoides Mart.), plantas nativas de porte herbáceo/ arbustivo e por fim, as arbóreas nativas, jatobá (Hymeneaea stigonocarpa Mart. ex Hayne), tingui (Magonia pubescens A. St.-Hil.) e o barbatimão (Stryphnodendron adstringens (Mart.) Coville).

Verifica-se que 19\% dos usos discriminados são para problemas respiratórios, $18 \%$ para infecções, $9 \%$ para diarréias, $7 \%$ vermífugas, $8 \%$ depurativos sanguíneos. Três espécies foram citadas no combate ao câncer e seis espécies são usadas no tratamento de doenças sexualmente transmissíveis. 
Tabela 1. Espécies citadas com fins medicinais pela comunidade de Alto Paraíso de Goiás, GO, Brasil.

\begin{tabular}{|c|c|c|c|}
\hline Hábito/Espécie & Família & Nome popular & Usos \\
\hline \multicolumn{4}{|l|}{ Exóticas } \\
\hline Acanthospermum australe (Loef.) O. Ktze.* & Compositae & carrapicho & $\begin{array}{l}\text { anti-inflamatória, anti-séptico, infec- } \\
\text { ções intestinais }\end{array}$ \\
\hline Ageratum conyzoides L.* & Compositae & mentrasto & analgésica, anti-inflamatória, diarréia \\
\hline Aloe vera Mill & Liliaceae & babosa & $\begin{array}{l}\text { recuperar lesões, câncer, aumenta } \\
\text { imunidade }\end{array}$ \\
\hline Artemisia verlotorum Lamotte & Compositae & losna & catarros, cólicas, fígado, rins, bexiga \\
\hline Baccharis trimera DC.* & Compositae & carqueja & fígado, digestão \\
\hline Bidens pilosa $\mathrm{L}$. & Compositae & picão & $\begin{array}{l}\text { depurativo, diabete, icterícia, } \\
\text { hemorróida }\end{array}$ \\
\hline Callendula officinalis L. & Compositae & calêndula & cicatrizante externo \\
\hline Carduus benedictus L. & Compositae & cardo-santo & $\begin{array}{l}\text { tônica, febrífuga, icterícia, antissépti- } \\
\text { ca, depurativa }\end{array}$ \\
\hline Cassia occidentalis L. & Leguminosae & fedegoso & diurético, depurativo, doenças de pele \\
\hline Cinnamomum canphora Tr. Nees \& Ebern & Lauraceae & cânfora & $\begin{array}{l}\text { estimulante, expectorante, anti } \\
\text { reumático }\end{array}$ \\
\hline Chenopodium ambrosioides L.* & Chenopodiaceae & mastruz & vermífuga, antibiótico, expectorante \\
\hline Cymbopogon citratus LK. & Gramineae & capim-limão & osteoporose, calmante, digestivo \\
\hline Echinodorus grandiflorus Micheli* & Alismataceae & congonha-do-campo & depurativa, reumatismo, sífilis \\
\hline Foeniculum vulgare Gaetn & Umbelifera & funcho & $\begin{array}{l}\text { cólicas, carminativas, diurético, } \\
\text { digestivo }\end{array}$ \\
\hline Lavandulla officinalis Choix & Labiatae & alfazema & $\begin{array}{l}\text { carminativa, antisséptica, balsâmica, } \\
\text { anti-espasmódica }\end{array}$ \\
\hline Marsypianthes chamaedrys (Vall) Ktz. & Labiatae & alfavaca & estimulante, antiespasmódica \\
\hline Matricaria chamomilla $\mathrm{L}$. & Compositae & camomila & calmante, pressão alta, insônia \\
\hline Maytenus ilicifolia $\mathrm{M}$ & Celastraceae & espinheira-santa & $\begin{array}{l}\text { analgésico, estomacal, antiácido, } \\
\text { antisséptico, cicatrizante }\end{array}$ \\
\hline Melinis minutiflora Beauv. & Gramineae & capim-gordura & osteoporose \\
\hline Carapa guianensis Aubl. & Meliaceae & andiroba & $\begin{array}{l}\text { vermífuga, feridas ouvido, sinusite, } \\
\text { herpes bucal }\end{array}$ \\
\hline Mentha piperita $\mathrm{L}$. & Labiateae & hortelã & vermífuga, estimulante, tônica \\
\hline Mentha pulegium L. & Labiateae & poejo & catarros, sistema nervoso \\
\hline Mikania glomerata Spreng. & Compositae & guaco & tosse, gripe, bronquite \\
\hline Peamus boldus Aut & Monimiaceae & boldo & fígado, digestivo \\
\hline Phyllanthus niruri Vell. & Euphorbiaceae & quebra-pedra & dissolve cálculos biliares \\
\hline Rosmarinus officinalis L. & Labiateae & alecrim & energético, reconstituinte \\
\hline Ruta graveolens L. & Rutaceae & arruda & $\begin{array}{l}\text { vermífuga, micoses, digestão, enema- } \\
\text { goga, hemorróidas }\end{array}$ \\
\hline Salvia officinalis L. & Labiateae & sálvia & $\begin{array}{l}\text { adstringente, tônica, digestiva, ener- } \\
\text { gética }\end{array}$ \\
\hline Sambucus nigra L. & Caprifolicaceae & sabugueiro & $\begin{array}{l}\text { resfriados, catapora, sarampo, escar- } \\
\text { latina }\end{array}$ \\
\hline Stachytarpheta sp. & Verbenaceae & gervão & $\begin{array}{l}\text { tônica, febrífuga, infecções, vermífuga, } \\
\text { reduz colesterol }\end{array}$ \\
\hline Symphytum officinale L. & Boraginaceae & confrei & inflamação externa \\
\hline Zingiber officinale Roscoe & Zingiberaceae & gengibre & $\begin{array}{l}\text { náusea, estômago, hemorragia, } \\
\text { expectorante }\end{array}$ \\
\hline \multicolumn{4}{|l|}{ Nativa/herbácea-arbustiva } \\
\hline Achillea millenifolium L. & Compositae & mil-folhas & $\begin{array}{l}\text { cicatrizante, úlceras, varizes, manchas } \\
\text { de pele }\end{array}$ \\
\hline Achyrocline satureoides DC. & Compositae & macela & $\begin{array}{l}\text { resfriado, estômago, sudorífera, prisão } \\
\text { de ventre, distúrbios uterinos, efeito } \\
\text { hipotensivo e espasmolítico }\end{array}$ \\
\hline Anemopaegma arvense (Vell.) Stellf. & Bignoniaceae & catuaba & $\begin{array}{l}\text { estimulante sexual, tônico do sistema } \\
\text { nervoso }\end{array}$ \\
\hline Clitoria guianensis Benth. & Leguminosae & vergateza & afrodisíaco, tônico do sistema nervoso \\
\hline Aristolochia cymbefere Barb. Rodr. & Aristolochiaceae & milhona & tônico do sistema nervoso \\
\hline
\end{tabular}


Tabela 1 (continuação)

\begin{tabular}{|c|c|c|c|}
\hline Hábito/Espécie & Família & Nome popular & Usos \\
\hline Baccharis dracumculifolia DC. & Compositae & alecrim-do-campo & febres, tônica \\
\hline Bacopa sp. & Scrophulariaceae & vassourinha & resfriado \\
\hline Bulbostylis paradoxa (Spreng.)Lindm. & Cyperaceae & barba de bode & gripe, febre alta \\
\hline Camarea affinis A. St.-Hil. & Malpighiaceae & pé-de-perdiz & inflamações uterinas, partos \\
\hline Capsella bursa-pastois (L.) & Cruciferaceae & panacéia & $\begin{array}{l}\text { adstringente, disenteria com sangue, } \\
\text { hemorragias }\end{array}$ \\
\hline $\begin{array}{l}\text { Cochlospermum regium (Mart. ex Schran K.) } \\
\text { Pilger }\end{array}$ & Cocholospermaceae & algodãozinho & $\begin{array}{l}\text { inflamações uterinas, vias urinárias, } \\
\text { diarréia }\end{array}$ \\
\hline Costus spicatus Sw. & Zingiberaceae & cana-do-brejo (Periná) & $\begin{array}{l}\text { diurético, hérnias, emolientes, } \\
\text { contusões e inchaços }\end{array}$ \\
\hline Duguetia furfuracea (A. St.-Hil.) & Annonaceae & beladona & calmante, rins \\
\hline Gomphrena officinalis Mart. & Amaranthaceae & para-tudo & febre, gripe, asma, picada de cobra \\
\hline Hybanthus lanatus (A. St.-Hil.) Bail. & Violaceae & papaconha & $\begin{array}{l}\text { gripe, febre, broncopneumonia, } \\
\text { disenteria }\end{array}$ \\
\hline Ipomoea sp. & Convolvulaceae & batata-de-purga & $\begin{array}{l}\text { prisão-de-ventre, descalcificação, } \\
\text { osteoporose }\end{array}$ \\
\hline Lantana lilacina Desf. & Verbenaceae & cambará & $\begin{array}{l}\text { inflamação de garganta, tosse, gripe, } \\
\text { bronquite e asma }\end{array}$ \\
\hline Lychnophora ericoides Less. & Compositae & arnica & inflamações, contusões \\
\hline Macrosiphonia velame (A. St.-Hil.). Arg. & Apocynaceae & velame-branco & $\begin{array}{l}\text { febres, intestino, coluna, depurativo, } \\
\text { anti-sifilítico }\end{array}$ \\
\hline Menora nodosa Miers. & Bignoniaceae & carobinha & Sarnas \\
\hline Palicourea coriacea (Cham.) K. Schum & Rubiaceae & douradinha & obesidade, rins, calmante \\
\hline Parietaria officinalis L. & Urticaceae & parietária & diurética, anti-inflamatória \\
\hline Passiflora sp. & Passifloraceae & passiflora & rins, fígado, cardíacos, calmante. \\
\hline Periandra mediterranea (Vell.) & Leguminosae & alcaçuz & $\begin{array}{l}\text { xarope gripe, inflamações vias } \\
\text { urinárias }\end{array}$ \\
\hline Piper aduncum L. & Piperaceae & aperta-ruão & $\begin{array}{l}\text { adstringente, tônica, queda útero, } \\
\text { diarréias }\end{array}$ \\
\hline Sisyrinchium vaginatum Spreng. & Iridaceae & capim-reis & febre, resfriado, intestino \\
\hline Spiranthela odorantissima A. St.-Hil. & Rutaceae & manacá & $\begin{array}{l}\text { inflamações uterinas, dor de cabeça, } \\
\text { estômago, fígado }\end{array}$ \\
\hline Vellozia flavicans Mart.ex Schult. & Velloziaceae & canela-de-ema & anti-inflamatório, anti-reumático \\
\hline Vernonia ferruginea Less. & Compositae & assa-peixe & $\begin{array}{l}\text { bronquite, asma, machucados, } \\
\text { depurativo }\end{array}$ \\
\hline Veronica persica $\mathrm{L}$. & Scrophulariaceae & verônica & $\begin{array}{l}\text { bronquite, tosse, problemas } \\
\text { pulmonares. }\end{array}$ \\
\hline Zeyhera digitalis (Vell.) Hochn. & Bignoniaceae & bolsa-de-pastor & anti-sifilítico, antiblenorrágico \\
\hline \multicolumn{4}{|l|}{ Nativa/ arbórea } \\
\hline Amburana cearensis (Fr. Allem.) & Leguminosae & $\begin{array}{l}\text { imburana, amburana, } \\
\text { cerejeira }\end{array}$ & $\begin{array}{l}\text { icterícia, expectorante, fígado, vesícula, } \\
\text { indigestão }\end{array}$ \\
\hline Anadenanthera falcata (Benth.) & Leguminosae & angico & inflamação uterina, doenças venéreas \\
\hline Annona crassiflora Mart. & Annonaceae & araticum & inseticida \\
\hline Bauhinia fortificata Link & Leguminosae & unha-de-vaca & $\begin{array}{l}\text { diabete, diurético, rins, anti } \\
\text { hemorrágico, coluna, inchaço no } \\
\text { corpo }\end{array}$ \\
\hline Brosimum gaudichaudii Tréc. & Moraceae & mama-cadela & $\begin{array}{l}\text { coluna, sangue, infecções, dermatites, } \\
\text { viroses animais }\end{array}$ \\
\hline Byrsonima verbascifolia Rich. Ex Juss. & Malpighiaceae & murici & diarréia \\
\hline Cariniana estrellensis (Raddi) & Lecythidaceae & jequitibá & $\begin{array}{l}\text { doenças venéreas, diarréias, anginas, } \\
\text { leucorréias, hemorragias uterinas, } \\
\text { afecções boca e garganta. }\end{array}$ \\
\hline Caryocar coriaceum Wittm. & Caryocaraceae & pequi & tônico, gripes e tumores \\
\hline Casearia sylvestris Planch. & Flacourtiaceae & erva-de-teiú & $\begin{array}{l}\text { anti-séptica e febrífuga, sífilis, } \\
\text { depurativo sangue e cicatrizante }\end{array}$ \\
\hline Cecropia pachystachia Trécul & Cecropiaceae & embaúba & $\begin{array}{l}\text { expectorante, antidiabético, cardio- } \\
\text { tônica }\end{array}$ \\
\hline
\end{tabular}


Tabela 1 (continuação)

\begin{tabular}{|c|c|c|c|}
\hline Hábito/Espécie & Família & Nome popular & Usos \\
\hline Copaifera langsdorffii Desf. & Leguminosae & copaíba & óleo cicatrizante, tumores, contusões \\
\hline Croton adenodontus (M. Arg.) M. Arg. & Euphorbiaceae & alcanforeira & $\begin{array}{l}\text { inflamação nos olhos, desidratação, má } \\
\text { digestão }\end{array}$ \\
\hline Croton urucurana & Euphorbiaceae & sangra-d’água & câncer e feridas externas \\
\hline Curatella americana $\mathrm{L}$. & Dilleniaceae & sambaíba, lixeira & resfriado, cicatrização feridas e úlceras \\
\hline Dimorphandra mollis Benth. & Leguminosae & fava-danta & $\begin{array}{l}\text { cicatrizante, provoca contrações } \\
\text { uterinas, adstringente, tóxico em altas } \\
\text { doses }\end{array}$ \\
\hline Dipteryx alata Vog. & Leguminosae & baru & $\begin{array}{l}\text { anti-reumático, tônica, regulador } \\
\text { menstrual }\end{array}$ \\
\hline Erythrina verna Vell. & Leguminosae & mulungu & bronquite, fígado, baço \\
\hline Guazuma ulmifolia Lam. & Sterculiaceae & mutamba & limpeza do couro cabeludo \\
\hline Hancornia speciosa Gomez & Apocynaceae & mangaba & $\begin{array}{l}\text { cólica menstrual, luxações e } \\
\text { hipertensão }\end{array}$ \\
\hline Hymenaea stigonocarpa Mart. ex Hayne. & Leguminosae & jatobá & $\begin{array}{l}\text { depurativo, anti inflamatório, } \\
\text { estimulante de apetite, fortificante rico } \\
\text { em ferro }\end{array}$ \\
\hline Kielmeyera coriacea (Spr.) Mart. & Clusiaceae & pau-santo & para olhos, vermífugo \\
\hline Lafoensia pacari A. St.-Hil. & Lythraceae & pacari & cicatrizante \\
\hline Magonia pubescens A. St.-Hil. & Sapindaceae & tingui & $\begin{array}{l}\text { sabão para dermatites, seborréia, } \\
\text { inseticida e mata piolho }\end{array}$ \\
\hline Mauritia flexuosa Linn.f. & Palmae & buriti & $\begin{array}{l}\text { energético e vermífugo, queimaduras } \\
\text { de pele, ajudando na cicatrização, anti- } \\
\text { reumático }\end{array}$ \\
\hline Melanoxylon brauna Schott. & Leguminosae & braúna & $\begin{array}{l}\text { diarréias, hemorragias uterinas, } \\
\text { hemoptises e ação vaso-constritora }\end{array}$ \\
\hline Myracrodruom urundeuva (Engler) Fr. Allem. & Anacardiaceae & aroeira & $\begin{array}{l}\text { inflamações, rins, estômago, aparelho } \\
\text { urinário, cicatrizante }\end{array}$ \\
\hline Psidium myrsinoides Berg. & Myrtaceae & araçá & diarréia \\
\hline Pterodon pubescens Benth. & Leguminosae & sucupira & inflamações na garganta, \\
\hline Qualea grandiflora Mart. & Vochysiaceae & pau-terra & ferimentos, inflamações. \\
\hline Rauwolfia selowii Müll. Arg. & Apocynaceae & casca de anta & hipotensor, tônico digestivo \\
\hline Siparuna guianensis Aublet. & Monimiaceae & negramina & coluna, reumatismo, artrite \\
\hline Strychnos pseudoquina A. St.-Hil. & Loganiaceae & quina & $\begin{array}{l}\text { afrodisíaca e tônica, cólicas, } \\
\text { depurativo, banho facilita o parto, } \\
\text { anti- inflamatório, fígado, baço } \\
\text { estômago }\end{array}$ \\
\hline Stryphnodendron adstringens (Mart.) Cov. & Leguminosae & barbatimão & $\begin{array}{l}\text { anti-séptico, adstringente, anti- } \\
\text { inflamatório }\end{array}$ \\
\hline Tabebuia aurea (Mart.) Bur. & Bignonicaceae & ipê & anti-inflamatório \\
\hline Tapirira guianensis Aubl. & Anacardiaceae & pau-pombo & banhos para peles ressecadas \\
\hline Vochysia rufa Mart. & Vochysiaceae & pau-doce & resfriado, vermífugo \\
\hline
\end{tabular}

*Espécie ruderal no Bioma, conforme Mendonça et al. (1998)

As tradicionais garrafadas também elaboradas pelos moradores da região apresentam uma gama diversificada de utilização na medicina popular. Algumas delas se destinam exclusivamente para o tratamento de doenças de origem brônquio-respiratória, enquanto outras, para as infecções uro-genitais, problemas de coluna, fortificantes, vermífugos, impotência sexual, afrodisíaco, depurativos sangüíneos. Essas garrafadas foram facilmente encontradas nos estabelecimentos comerciais da cidade (farmácias e mercados) e também nas feiras populares. $\mathrm{O}$ seu preço em Alto Paraíso atingia em média R \$ 15,00 o litro em julho/1999.

Outros produtos igualmente comercializados na região na mesma época, como os sabonetes de plantas medicinais eram vendidos a $\mathrm{R} \$ 3,00$ a unidade. Os chás, dessa mesma categoria de plantas eram encontrados a preços que variavam de $\mathrm{R} \$ 5,00$ a 10,00 a embalagem de 100 gramas. Os travesseiros, um produto tradicional e fabricado na região com plantas 


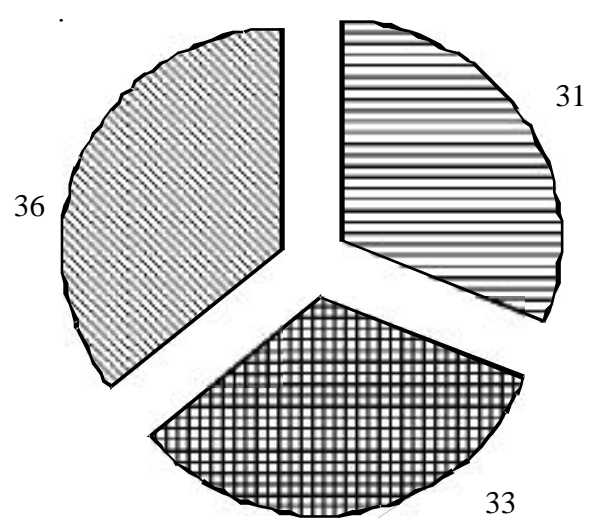

Figura 1. Percentual de exóticas e nativas dentre 103 espécies citadas no Levantamento etnobotânico na região de Alto Paraíso de Goiás, GO, Brasil. 目 = Exóticas; 㘞 = Nativas herbáceoarbustivas; = Nativas arbóreas.

medicinais (macela e eucaliptos), que são inclusive exportados, à época, para alguns países, por suas qualidades terapêuticas vendidos entre $\mathrm{R} \$ 7,00 \mathrm{e}$ $\mathrm{R} \$ 15,00$ a unidade. As pomadas e os cremes confeccionados com as plantas do cerrado e algumas oriundas de outras regiões (principalmente a amazônica), comercializadas a R \$ 5,00 a embalagem. O jatobá, conhecido por suas propriedades terapêuticas, faz parte também da gama desses produtos, tradicionais e a sua seiva, forma como é comercializado na região, custava $\mathrm{R} \$ 10,00$ o litro.

Em virtude desse dinamismo e potencial econômico envolvendo o extrativismo vegetal na região do entorno do Parque Nacional da Chapada dos Veadeiros (Silva et al. 2001), surgiram algumas iniciativas locais no sentido de organizar e fortalecer tanto a sua produção quanto comercialização. Por exemplo, O Tom das Ervas, o mais tradicional produtor e conhecedor da flora medicinal do cerrado em Alto Paraíso, tinha sob sua responsabilidade atender às necessidades de um cliente em Brasília com encomendas semanais de 50 garrafadas para usos diversificados. O Totoru House, restaurante e comércio foram, até recentemente, um exportador de chás medicinais e travesseiros aromáticos e o Herbário Millefolium vem produzindo chás, garrafadas e outros produtos tradicionais que gradativa e progressivamente conquistam o comércio de produtos naturais de Brasília. O uso da biodiversidade nativa é intenso com $69 \%$ das espécies mencionadas como úteis pertencentes à flora nativa.

Apesar do grande potencial de exploração extrativista vegetal, estes recursos estão sendo subutilizados, sem um programa eficiente de manejo contemplando espécies que podem ser comercializadas com as indústrias alimentícias, fitoterápicas e farmacêuticas.

Existem condições favoráveis para a elaboração de programas que visem incentivar/financiar empresas familiares para o manejo da flora do cerrado, devido inclusive à população ter o hábito de utilização cotidiana. A iniciativa de alguns moradores para a confecção de produtos medicinais atinge o comércio de Brasília e a exportação de chás. Ademais, a prática do ecoturismo nesta região propicia maior abertura e viabilização de comércio de produtos secundários vegetais.

Vários projetos de aproveitamento econômico de plantas do cerrado foram implantados no município de Alto Paraíso, especialmente através de Organizações Não Governamentais. O malogro ou a demora para implantação efetiva dessas iniciativas ocorreu-se principalmente à falta de uma visão de conjunto dos aspectos enfocados, ficando quase restrito à coleta $\mathrm{e}$ transformação dos produtos sem uma visão mais ampla de mercado consumidor.

A exemplo das indústrias Klabin, no Paraná, que manejam 73 mil hectares de florestas nativas para a produção de medicamentos fitoterápicos, dos Hospitais que plantam e utilizam a flora para a elaboração dos remédios naturais, das indústrias farmacêuticas internacionais que se valem dos conhecimentos do povo nativo para a pesquisa das drogas, recomenda-se a elaboração de projetos de manejo e domesticação das plantas medicinais do cerrado da região de Alto Paraíso.

Avaliando-se os estudos etnobotânicos, muitas espécies exóticas são utilizadas para tratar enfermidades e compõem inúmeros medicamentos, recomenda-se que seja considerada a hipótese de desenvolver programas de cultivos em pequenas áreas de plantas medicinais para uso específico de produção dos medicamentos.

\section{Agradecimentos}

Ao Dr. Manoel Cláudio da Silva Júnior, pela dedicação ao ofício de mestre; à Sra. Roberta Mendonça, Curadora do Herbário do IBGE; aos professores do Departamento de Engenharia Florestal, em especial Alba Valéria Resende, que se empenhou em participar da equipe de coleta de dados; a Edson Cardoso, Newton Rodrigues, pelo auxílio nos trabalhos de campo; ao Projeto Conservação e Manejo da 
Biodiversidade do Bioma Cerrado, por financiar as excursões à Fazenda Horta com recursos do DFID U.K.; ao FNMA, por apoiar o projeto Biogeografia do Bioma Cerrado, que disponibilizou veículos e equipamentos para as excursões; ao Dr. Sebastião Kengen, por compilar bibliografia sobre produtos secundários florestais; a Paulo Benincá de Salles e ao Dr. Luiz Carlos Couto, e a meus pais, pelo apoio incondicional.

\section{Referências bibliográficas}

Almeida, S.P.; Proença, C.E.B.; Sano, S.M. \& Ribeiro, J.F. 1998. Cerrado: Espécies vegetais úteis. Planaltina, EMBRAPA-CPAC.

Alexiades, M.N. \& Sheldon, J.W. 1996. Ethnobotanical Research: A Field Manual. Bronx, New York, The New York Botanical Garden.

Dardenne, M.A. \& Faria, A. 1985. Estratigrafia do Grupo Paranoá na região de Alto Paraíso - GO. Pp. 65-71. In: Anais do $2^{\circ}$ Simpósio de Geologia do Centro-Oeste. Goiânia, Geologia do Pré-Cambriano. SBG/NCOP.

Elisabetsky, E. 1986. New directions in ethnopharmacology. Journal of Ethnobiology 6(1): 121-128.

Etkin, N.L. 1988. Etnopharmacology: Biobehavioral approaches in the antropologycal study fo indigenous medicines. Annual Review of Antropology 17: 23-42.

Etkin, N.L. 1990. Etnopharmacology: Biological and behavioral perspectives in the study of indigenous medicines. Pp. 149-158. In: T.M. Johnson \& C.F. Sargent (eds.). Medical antropology: A handbook of theory and method. New York, Greenwood Press.

Felfili, J.M.; Silva Júnior, M.C.; Filgueiras, T.S. \& Nogueira, P.E. 1998. Comparison of cerrado (sensu stricto) vegetation in central Brazil. Ciência e Cultura 50(4): 237-243.

Felfili, J.M.; Silva Júnior, M.C.; Rezende, A.V.; Nogueira, P.E.; Walter, B.W.T.; Silva, M.A. \& Encinas, J.I. 1997. Comparação florística e fitossociológica do cerrado nas Chapadas Pratinha e dos Veadeiros. Pp. 6-11. In: L. Leite \& C. Saito. Contribuição ao conhecimento ecológico do cerrado. Brasília, Universidade de Brasília.
Guarim Neto, G.; Santana, S.R. \& Silva, J.V.B. 2000. Notas etnobotânicas de espécies de Sapindaceae Jussieu. Acta Botanica Brasilica 14(3): 327-334.

Herrick, J.W. 1983. The symbolic roots of three potent Iroquois medicinal plants. Pp. 134-155. In: L. RomanucciRoss; D.E. Moerman \& L.R. Tancredi (eds.). The antropology of medicine: From culture to method. South Hadley, J.F. Bergin.

IBGE. 1987. Produção da extração vegetal e da silvicultura. Rio de Janeiro, v.2.

IBGE. Anuário estatístico do Brasil. 1984, 1985, 1987, 1992. Rio de Janeiro.

Marimon, B.S. \& Felfili, J.M. 2001. Ethnobotanical comparisonof Pau Brasil (Brosimum rubescens Taub.) forests in a Xavante Indian and a Non-Xavante comunity in eastern Mato Grosso State , Brazil. Economic Botanic 55(4): 555-569.

Martin, G.J. 1995. Ethnobotany - A methods manual. London, Ed. Chapman \& Hall.

Mendonça, R.; Felfili, J.M.; Walter, B.M.T.; Silva Júnior, M.C.; Rezende, A.V.; Filgueiras, T.S. \& Nogueira, P.E.N. 1998. Flora vascular do Cerrado. Pp. 287-556. In: S. Sano \& S. Almeida (eds.). Cerrado: ambiente e flora. Planaltina, EMBRAPA-CPAC.

Munhoz, C.B.R. \& Proença, C.E. Composição florística do Município de Alto paraíso de Goiás na Chapada dos Veadeiros. Boletim do Herbário Ezechias Paulo Heringuer 3: 102-150.

Meyers, N. 1983. Tropical moist forests; over-exploited and under-utilized? Forest Ecology and Management 6. 59-79.

Prance, G.T. 1991. What is ethnobotany today? Journal of Ethnopharmacology.

Prance, G.T.; Balée, W.; Boom, B.M. \& Carneiro, R.L. 1987. Quantitative ethnobotany and the case for conservation in Amazonia. Conservation Biology 1: 296-310.

Prefeitura Muicipal de Alto Paraíso de Goiás. 1999. Plano Diretor da Cidade de Alto Paraíso de Goiás/GO. Coord: Souza, A.

Principe, P.P. 1985. The value of biological diversity among medicinal plants. Paris, Environment Directorate, Organization for Economic Cooperation and Development.

Silva, S.R.; Silva, A.P.; Munhoz, C.M.; Silva Júnior, M.C. \& Medeiros, M.B. 2001. Guia de plantas do cerrado utilizadas na Chapada dos Veadeiros. Brasília, WWFBrasil. 